\title{
POSSIBILIDADES DE ENSINO DE BOTÂNICA EM UM ESPAC̣O NÃO-FORMAL DE EDUCAÇÃO NA PERCEPC̣ÃO DE PROFESSORAS DE CIÊNCIAS
}

\author{
Rafaella Librelon de Faria* \\ Daniela Franco Carvalho Jacobucci* * \\ Renata Carmo Oliveira***
}

RESUMO: $O$ interesse por atividades e locais diferenciados para o ensino tem aumentado a procura por Museus de Ciências. A diversidade de informações encontradas nos espaços não-formais amplia as possibilidades de ensino e fortalece as relações com as escolas. O presente trabalho traz as concepções de professoras de Ciências sobre espaços não-formais de Educação e apresenta uma atividade chamada "Chá de Sentidos" com o tema Botânica, no Museu DICA, em Uberlândia - MG. As professoras apresentaram dificuldades em conceituar e distinguir o espaço formal do não-formal e vincularam o Museu DICA como um local complementar à escola. A atividade foi avaliada positivamente pelas professoras, mas, como uma forma de trabalhar o conteúdo curricular e não para simplesmente deflagrar o interesse pelos vegetais e ampliar as possibilidades de aprendizado de seus alunos, relacionando as experiências vivenciadas fora da escola com as da sala de aula.

Palavras-chave: Espaço não-formal de Educação; Ensino de Botânica; Concepção de Professores.

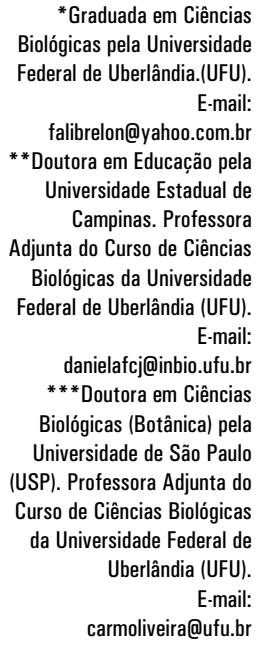

* Graduada em Ciências Biológicas pela Universidade Federal de Uberlândia.(UFU). E-mail: falibrelon@yahoo.com.br * *Doutora em Educação pela Universidade Estadual de Campinas. Professora Adjunta do Curso de Ciências Biológicas da Universidade Federal de Uberlândia (UFU). E-mail:

danielafcj@inbio.ufu.br * * *Doutora em Ciências Biológicas (Botânica) pela Universidade de São Paulo (USP). Professora Adjunta do Curso de Ciências Biológicas da Universidade Federal de Uberlândia (UFU). E-mail: carmoliveira@ufu.br

\section{POSSIBILITIES FOR BOTANY TEACHING IN A NON-FORMAL \\ EDUCATIONAL SPACE IN THE PERCEPTION OF SCIENCE TEACHERS}

ABSTRACT: The interest for alternative activities and places for teaching has increased the attendance in museums and Science centers. The diversity of information encountered in non-formal Education spaces expands teaching possibilities and strengthens the links with schools. The present work reads the conceptions of a group of Science teachers about nonformal spaces. Furthermore, it reports an activity on a Botany topic, which the group participated in the DICA Museum, in Uberlândia - MG. The teachers had difficulties to conceptualize and distinguish the formal and non-formal spaces and viewed the Museum as a complementary place to the school. The activity was evaluated positively by the teachers, but as a way to work the curriculum content and not simply to spark interest in plant Biology and expand the possibilities of learning of their students, relating their experiences outside school with the classroom.

Keywords: Non-Formal Education Spaces; Teaching of Botany; Teacher Conceptions. 


\section{INTRODUÇÃO}

Muito tem se falado sobre Espaços de Educação formal e não-formal. Entre os pesquisadores da área, não existe um consenso sobre um possível conceito. Para este trabalho, optamos pela definição que considera que: espaços formais de Educação dizem respeito à ambientes normatizados enquanto que os não-formais ocorrem em ambientes e situações interativas, construídos coletivamente, com participação opcional dos indivíduos. Assim, Educação Formal seria aquela ligada ao espaço escolar enquanto a não-Formal se daria em ambientes fora da escola, como Museus e Zoológicos (GOHN, 2006).

Para a mesma autora, a produção do conhecimento em espaços nãoformais, não ocorre pela absorção de conteúdos previamente sistematizados, objetivando ser apreendido, mas é gerado por meio da vivência de certas situações-problema. Com relação aos espaços de Educação não-formal, existem alguns aspectos que os tornam fundamentais para a promoção dessa proposta educacional. Isto porque o caráter de não formalidade dessas instituições permite uma maior liberdade na seleção e organização de conteúdos e metodologias, o que amplia as possibilidades da interdisciplinaridade e contextualização (GUIMARÃES; VASCONCELLOS, 2006).

Porém, é possível buscar parcerias com instituições de Educação Formal desde que sejam preservadas as identidades de cada local (FAHL, 2003). Para Marandino (2002), os Museus de Ciências têm sido cada vez mais consagrados como locais fundamentais para o desenvolvimento da Educação não-formal em Ciências. As atividades educativas desenvolvidas nesses espaços são de diferentes naturezas, e estratégias variadas têm sido propostas para realizá-las. Apesar dessa diversidade, um dos objetivos comuns a todos os Museus e Centros de Ciências é ensinar Ciências (GASPAR, 1993).

Entrevistas realizadas com professores que levaram seus alunos ao Museu de Astronomia e Ciências Afins (MAST) (GOUVEIA et al., 2001; QUEIROZ et al., 2003) e ao Museu Nacional do Rio de Janeiro (VIEIRA, 2005) mostraram que uma das principais expectativas dos professores em relação a esses espaços é que eles permitam aos alunos aprender conteúdos de uma forma menos teórica e apontando, dessa forma, uma relação entre a escola e o Museu.

Essa forte ligação entre espaço formal e não-formal pode ser explicada, em relação aos Museus e Centros de Ciências, pela análise histórica. A partir da década de 60 , vários financiamentos governamentais e de órgãos internacionais surgiram no cenário brasileiro, com o intuito de promover melhoria no Ensino de Ciências. Nesse contexto, os Museus de Ciências voltaram sua atenção para as necessidades dos professores dessa área, os responsáveis diretos pela melhoria do Ensino (GASPAR, 1993). Estava, dessa forma, estabelecido um vínculo entre professores e Museus de Ciências que persiste até hoje. Os professores esperam desses espaços ferramentas que permitam melhorar suas aulas e 
atraiam a atenção dos alunos para vários aspectos das Ciências e, em contrapartida, os Museus têm o público escolar como os principais grupos de visitantes.

A preocupação com a comunicação da exposição com o público escolar vem aumentando. Isso se deve, principalmente, pela demanda estabelecida pela escola que vem solicitando, de maneira mais sistemática, visitas de grupos de estudantes ao Museu e suas exposições, tornando esta prática mais comum no âmbito das ações educativas e culturais propostas na Educação formal (GRUZMAN; SIQUEIRA, 2007). Sabendo disso, é importante conhecer a opinião dos professores a respeito das atividades desenvolvidas nesses espaços.

Em Uberlândia (MG), o Museu Diversão com Ciência e Arte (DICA) da Universidade Federal de Uberlândia, criado em 2006, atende, prioritariamente, a escolares do Ensino Fundamental e Médio através de um acervo de instrumentos científicos, brinquedos e atividades produzidas por alunos de Graduação em Física e Ciências Biológicas.

Considerando a importância de se divulgar temas biológicos no museu e com o intuito de criar atividades que agucem a curiosidade do público visitante e que promovam uma interação entre os visitantes e o conhecimento presente em espaços não-formais de Educação, foi desenvolvida a atividade Chá de Sentidos. A atividade busca explorar os sentidos humanos com o uso de infusões (chá) de plantas medicinais.

Trabalhar com plantas aromáticas e/ou de uso na medicina popular, nos facilita provocar uma aproximação com os vegetais, pois sabemos que tais plantas são representativas na vida da maioria das pessoas.

Outro ponto que nos moveu a escolher os vegetais é a dificuldade apontada na literatura em trabalhar, na área das Ciências Naturais, com o conhecimento acerca dos vegetais. Apesar desses seres vivos estarem presentes nos ambientes que vivemos desde o início de nossas vidas, o interesse pelos vegetais é pouco evidente (WANDERSEE, SCHUSSLER, 2001).

Voltando nosso olhar para a escola, temos que o interesse ou a importância do desenvolvimento do conhecimento sobre os vegetais fica comprometido não só pelo distanciamento que as pessoas revelam dos vegetais mas, também, pelas dificuldades que os professores indicam acerca do tema.

Para Silva (2008), o ensino da Botânica desenvolvido nos dias atuais é, em sua grande parte, feito por meio de listas de nomes científicos e de palavras totalmente isoladas da realidade usadas para definir conceitos que, possivelmente, nem ao menos podem ser compreendidos pelos alunos e pelos professores. Kinoshita e colaboradores (2006) reconhecem que o ensino de Botânica caracteriza-se como muito teórico, desestimulante para os alunos e subvalorizado dentro do ensino de Ciências e Biologia.

Nesse trabalho buscamos conhecer o entendimento de professores de Ciências da cidade de Uberlândia sobre espaços não-formais de Educação e sua valorização para o processo de ensino-aprendizagem, enfocando-se aí a Botânica. 
Diante desse cenário de relações entre Ensino não-formal e Museu de Ciências e do nosso interesse de possibilitar uma abordagem interativa sobre os vegetais, nossos objetivos foram: a) conhecer as concepções dos professores do Ensino Fundamental sobre espaço não-formal e Educação não-formal e b) avaliar o potencial didático de uma atividade realizada no Museu da DICA para o ensino de Botânica.

\section{DELINEAMENTO METODOLÓGICO DA PESQUISA}

A presente pesquisa se configura como qualitativa. A interpretação dos dados foi realizada com base na análise de conteúdo que Minayo (2007) propõe como um conjunto de técnicas destinadas à descoberta do que está por trás dos conteúdos manifestos, indo além das aparências do que está sendo comunicado.

A análise dos conteúdos coletados e organizados passa primeiramente pela etapa do recorte, na qual os relatos são decompostos, para em seguida serem recompostos para melhor expressar sua significação. Os elementos recortados vão constituir as unidades de análise. A categorização final do conteúdo se refere a uma análise de reconsideração da alocação dos conteúdos e sua categorização a partir de um processo iterativo, característico do modelo circular da pesquisa qualitativa (LAVILLE \& DIONNE, 1999).

Os sujeitos envolvidos na pesquisa, professores do Ensino Fundamental, com garantias éticas do sigilo de seus nomes, obtiveram explicação prévia acerca do projeto de pesquisa (LÜDKE \& ANDRÉ, 1986). Os professores foram identificados com a letra "P" seguida de um número identificador.

Dezessete professoras de Ciências do Ensino Fundamental $\left(5^{\mathrm{a}}\right.$ a $8^{\mathrm{a}}$ série) de Escolas Municipais, Estaduais e Particulares de Uberlândia, foram convidadas a participar da pesquisa por mensagem eletrônica ou visita à escola. A pesquisa foi realizada em quatro etapas, sendo: (1) aplicação do Questionário I aos professores; (2) realização da atividade "Chá de Sentidos" para os professores; (3) aplicação do Questionário II; (4) análise e interpretação dos dados.

A coleta de dados foi realizada em dois momentos, a saber: (A) aplicação do Questionário I, realizado e entregue antes da atividade no Museu da DICA, composto por nove perguntas discursivas e uma de múltipla escolha, para investigar o que os professores entendem por espaço formal e não-formal de Educação, quais as possibilidades de interação entre esses espaços e quais as intencionalidades dos professores ao usar os espaços não-formais para o Ensino de Ciências e (B) realização da atividade proposta junto aos professores, seguida do registro das impressões, em diário de campo, pela pesquisadora. Aplicação do Questionário II aos professores, composto por sete questões discursivas, que visavam conhecer suas concepções ${ }^{1}$ sobre a utilização de Museus de Ciências 
como espaço para Ensino, a avaliação da atividade "Chá de Sentidos" nesse espaço e do potencial da mesma para o Ensino de Botânica. O retorno do Questionário II aconteceu via mensagem eletrônica ou pessoalmente. Todas as professoras que participaram do momento "A" foram convidadas a participar da segunda etapa do projeto. Os tópicos abordados nos Questionários I e II estão apresentados no quadro1.

Quadro 1. Tópicos dos Questionários I e ||

\section{Questionário II}

1) Em sua opinião, o que é Espaço Formal de Educação?

2) Em sua opinião, o que é Espaço não-Formal de Educação?

3) Você já levou seus alunos para espaços não-Formais de Educação? Qual(is)? Com que frequência?

4) Você acha que as dependências da escola como pátio, quadra, refeitório, são espaços não-Formais?

5) Com que intenção você levaria seus alunos a um espaço distinto do espaço escolar?

6) Você acha que é possível abordar um conteúdo programado durante uma visita a um espaço não-Formal?

7) Depois de uma visita a um Espaço não-formal, de que maneira você acha possível utilizar as informações adquiridas nesse espaço na abordagem do conteúdo programado de Ciências?

8) Como você vê sua atuação docente em uma visita a um espaço não-formal?

9) 0 que você espera encontrar em Museu de Ciências?

10) Quando programa uma visita a um espaço não-Formal é por quê:

() Já conhece o local e suas atividades.

() Tem vontade de conhecer o local e acha uma boa oportunidade de levar os alunos.

() A pedido dos alunos.

() Outro.

\section{Questionário II}

1) Qual sua opinião sobre a utilização do Museu da DICA para realização de atividades de Ciências?

2) 0 que você achou da atividade "Chá de Sentidos"?

Quais as suas impressões da atividade antes, durante e depois da sua apresentação?

3) É viável trazer seus alunos a esse espaço, para fazer essa atividade?

4) Caso julgasse adequado utilizar essa atividade em seu planejamento, como seria?

5) Depois de proporcionar aos seus alunos uma atividade como essa realizada no Museu, como você a utilizaria em sala numa aula de Botânica?

6) Que conceitos de Botânica você acha possível de serem trabalhados com essa atividade?

7) Quais são as suas sugestões para melhorar essa atividade?

\section{A atividade Chá de Sentidos}

A atividade é apresentada em dois momentos. No primeiro, os visitantes - as professoras - são submetidos à exploração dos sentidos por meio de chás e aromas e, em seguida, são convidados a visitar o canteiro de ervas aromáticas para reconhecerem as plantas utilizadas.

Para a atividade, desenvolvida em quatro etapas com as professoras de nossa pesquisa, foram escolhidas três ervas aromáticas: hortelã-pimenta (Mentha piperita L.), erva-cidreira (Melissa officinalis L.) e poejo (Mentha pulegium L.).

Etapa 1. OLFATO: o participante escolhe uma caixa $(8 \times 8 \times 3 \mathrm{~cm})$, identificada com uma letra - a, b ou c - contendo uma das ervas in natura picada e é convidado a sentir o aroma. 
Etapa 2. VISÃO: ao participante são apresentados três frascos transparentes, identificados por três letras - a, b, c - contendo as infusões produzidas a partir de cada uma das três ervas. A indicação $(\mathbf{a}, \mathbf{b}, \mathbf{c})$ nos potes não corresponde àquelas presentes nas caixas. Sendo assim, o participante tenta associar a cor do chá com a erva que encontrou na caixa escolhida.

Etapa 3. PALADAR: nessa etapa, o participante recebe uma venda de pano preto para os olhos e, de olhos fechados e vendados, é orientado a tampar o nariz enquanto degusta uma pequena porção do chá oferecido pela monitora. O participante é informado da temperatura e a falta de adoçantes e ingere uma pequena quantidade dos três chás. Após ingerir a infusão, as professoras foram questionadas sobre qual dos chás corresponderia ao da erva que estava na caixa que cada uma escolheu na etapa um.

Etapa 4. Por fim, as participantes foram informadas sobre as correspondências certas de cada erva nas etapas um, dois e três.

No segundo momento as professoras foram encaminhadas ao canteiro de ervas aromáticas e convidadas a encontrarem as ervas que experimentaram nas etapas anteriores. Junto às plantas, o visitante é estimulado a tocá-las para que possa sentir a textura e o aroma exalado pelo toque. Nessa etapa o tato auxilia no reconhecimento visual e olfativo do vegetal. O canteiro no Museu DICA possibilita ainda o conhecimento ou reconhecimento de outras espécies.

\section{Criação do canteiro de ervas aromáticas}

Um canteiro sensorial, além de compor o jardim do espaço DICA, altera positivamente a estética local e possibilita ao visitante um contato direto com as plantas.

O canteiro montado no Jardim do Museu da DICA é muito simples e compreende duas metades de um tambor de latão, de 110 x 48 × $25 \mathrm{~cm}$, afixadas com pés a uma altura de $60 \mathrm{~cm}$ do chão, para que as plantas fiquem acessíveis a manipulação, como pode ser visto na figura abaixo.

Figura 1. (A) Disposição dos canteiros de ervas aromáticas (B) e (C) Visão superior dos conteiros

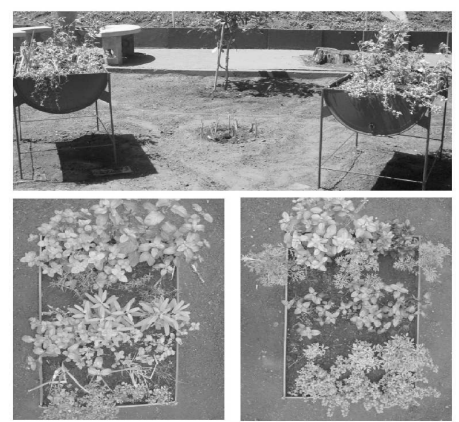


As espécies utilizadas são comumente usadas em chá ou temperos e facilmente adquiridas com baixo custo: levante (Mentha sp.), alecrim (Rosmarinus officinalis L.), sálvia (Salvia officinalis L.), hortelã-pimenta (Mentha piperita L.), cebolinha (Allium schoenoprasum L.), orégano (Origanum vulgare L.) e salsinha (Petroselinum crispum (Mill.) Nyman ex AW Hill.), manjericão (Ocimum basilicum L.), Losna (Artemísia absinthium L.), erva-cidreira (Melissa officinalis L.), arruda (Ruta graveolens L.) e poejo (Mentha pulegium L.). Além disso, entre os tambores, no chão, foi plantado capim-cidreira (Cymbopogon citratus (DC) Stapf.).

Por serem de fácil acesso e de baixo custo, o professor pode adquirilas e/ou cultivá-las na escola para abordagem dos conteúdos de Botânica.

\section{RESULTADOS E DISCUSSÃO}

Das dezessete professoras convidadas, treze professoras responderam o questionário e cinco dessas participaram da atividade Chá de Sentidos e responderam o Questionário II. Foram agendados dois horários de forma que melhor atendesse às participantes.

A análise dos resultados será dividida em duas etapas de acordo com os objetivos propostos.

\section{Concepções dos professores sobre espaços não-formais de Educação}

As análises seguintes foram baseadas nas respostas obtidas no Questionário I e da primeira pergunta do Questionário II.

De acordo com as respostas obtidas no questionário I as professoras associam espaço formal de Educação principalmente ao ambiente da sala de aula com justificativas como: "Um lugar onde existam mais regras" (P3); "É o local habitual, como sala de aula [...]" (P9). Assim, o espaço formal esta associado a modelos tradicionais de Educação onde, para Krasilchik (2004), o professor é a autoridade responsável pelo Ensino. Percebe-se que as professoras delimitam o ambiente físico da sala de aula como sendo o espaço de Educação formal. Para Gohn (2006) e Jacobucci (2008) o espaço formal é o espaço escolar, que está relacionado às Instituições Escolares da Educação Básica e do Ensino Superior, definidas na Lei 9394/96 de Diretrizes e Bases da Educação Nacional. É a escola, com todas as suas dependências: salas de aula, laboratórios, quadras de esportes, biblioteca, pátio, cantina e refeitório.

Quanto ao conceito de espaço não-formal de Educação encontramos dois padrões principais de respostas: um que relaciona o não-formal a tudo que acontece fora da escola, ou seja, "[...] fora do espaço limitado da escola." como resume P8 e outro que restringe o espaço ao ambiente fora da sala de aula, considerando assim como não-formal os espaços "[...] que ultrapassam os limites da sala de aula." (P1). 
Não há um consenso sobre qual é o limite do espaço escolar entre os entrevistados. $\mathrm{O}$ espaço não-formal acaba sendo relacionado a ambientes onde não exista formalismo, no sentido de ser um espaço no qual as regras não sejam tão explícitas como acontece dentro de uma sala de aula, daí encontramos a quadra, o pátio e o momento do recreio citados pelas professoras como sendo espaços não-formais de Educação.

Embora as professoras consigam elaborar prontamente um conceito sobre espaços não-formais de Educação, há dificuldades em delimitar o que seria o espaço escolar, por isso acabam considerando alguns espaços dentro da escola como não-formais. A professora P7 exemplifica espaços formais da seguinte maneira: "[...] sala de aula, laboratórios, quadras, museus." e espaços não-formais como sendo "[...] pátio da escola, horta, jardim, cantina.". Percebemos a dificuldade na distinção desses espaços, já que a quadra é apontada como formal enquanto o pátio é considerado não-formal, sendo que, no entanto, ambos estão inseridos no ambiente escolar. Para Jacobucci (2008) apesar de o nome "espaço não-formal de Educação", ou sua abreviação como "espaço não-formal”, ser constantemente usado para definir lugares em que pode ocorrer uma Educação não-formal, a conceitualização do termo não é óbvia.

Quando perguntadas sobre a que tipos de espaços não-formais as professoras levam seus alunos, os locais mais citados foram: os Parques Municipais, Museu de Biodiversidade do Cerrado (UFU), Museu de Minerais e Rocha (UFU), visitas a Usinas Hidroelétricas e a estação de tratamento de água e esgoto, além de viagens. Embora prevaleça a indefinição sobre os limites do espaço escolar, todas as respostas abordaram espaços não-formais fora do espaço escolar. Provavelmente isso tenha acontecido pelo direcionamento da pergunta, que indagava se elas já tinham levado os alunos a espaços não-formais de Educação. Talvez a expressão levado a algum lugar as tenham remetido ao movimento de retirar os alunos da escola.

Para as professoras a visita ao espaço de Educação não-formal é encarada como uma oportunidade de socialização com os alunos onde elas podem "[...] estabelecer uma relação mais próxima do aluno." (P4) o que corrobora com Krasilchik (2004) onde relata que o trabalho realizado fora da escola permite entre outras coisas aumentar a interação professor-aluno.

A possibilidade de ligar teoria à prática é o principal elemento que leva as professoras a procurar um espaço distinto do escolar "[...] ver na prática e não apenas na teoria." (P10) e "[...] vivenciando eles (os alunos) aprendem muito mais que apenas escutando." (P3) foram as justificativas mais usadas para ressaltar a importância de se levar os alunos a espaços não-formais. Os Museus proporcionam a experiência com objetos que podem gerar motivação e curiosidade além de acentuar o espírito crítico em relação à realidade (ALMEIDA, 1997).

Porém, vale ressaltar que levar os alunos ao Museu à procura de vivências práticas é diferente de quando um professor leva seus alunos ao mesmo espaço à procura de aulas práticas. Guimarães (2006) adverte para que não sejam 
submetidos à Educação não-formal referenciais estritamente escolares e viceversa. Museus e escolas são diferentes espaços, portanto, com diferentes propostas educacionais (VIEIRA, 2005).

O que se percebe é que, ao levar alunos a espaços não-formais, as professoras tendem a esperar do aluno uma postura escolar principalmente quanto à forma de avaliação. $\mathrm{O}$ uso de relatórios depois de uma visita é a forma mais comum encontrada pelas professoras para fazer uma ponte entre o que eles observaram na visita com os conteúdos vistos em sala de aula, além de ser uma maneira de cobrar disciplina. Durante as visitas com alunos ao MAST, os professores tiveram em sua maioria atitudes como: colocar os estudantes em fila, mantê-los calados, mandar copiar textos e legendas e até mesmo coibir respostas errôneas (QUEIROZ et al, 2003).

Normalmente, a preparação dada aos alunos pelos professores acaba se restringindo a como se comportar em um museu (ALMEIDA, 1997). Quando as professoras levam seus alunos a espaços não-formais existe uma necessidade de controle sobre o que os alunos devem fazer e, assim, encontramos sugestões como "[...] criaria um roteiro a ser respondido pelos alunos sobre o Museu e suas atividades." (P2), em resposta à pergunta de como utilizar a visita a um Museu no planejamento escolar. Almeida (1997) adverte que, muitas vezes, as expectativas de professores, alunos e equipe do Museu são diferentes e que a estrutura oferecida pelos espaços pode acabar sendo pouco explorada pela extrema descontração dos alunos e/ou rigor dos professores.

Quando levam seus alunos a esse tipo de espaço, os professores costumam não interferir quando existe algum tipo de guia ou monitor. Marandino (2003) adverte que é importante compreender que Museus não são escolas e mediadores não são professores, mas nada impede que o professor utilize-se do Museu da forma que achar mais conveniente. $\mathrm{O}$ professor tem um importante papel dentro do processo de aprendizagem, devendo atuar como mediador entre os saberes dos alunos e o conhecimento científico. Estes saberes ligados a um prévio poderão construir outro (VIEIRA, 2005), e entendemos que esse conhecimento prévio pode ser relativo àquele que o professor sistematizou em sala de aula.

A criação de roteiros ou condutas sociais estabelecidas antes ou durante uma visita pode refletir a preocupação do professor com seu papel na aprendizagem dos alunos e, assim, ele acaba usando as mesmas ferramentas para avaliação empregadas nos espaços formais, entre elas a disciplina e a prova, roteiros ou relatórios. A dificuldade de praticar esse conhecimento sobre espaços para o Ensino, provocadas muitas vezes pela rotina profissional, leva a uma dificuldade em buscar novas formas de avaliação que seriam mais adequadas a uma visita a um espaço diferente da escola.

Quando um aluno vai a uma visita com um roteiro a ser seguido, a função de entretenimento do espaço acaba sendo diminuída, pois a possibilidade de livre escolha é perdida mediante as exigências do professor. A experiência em 
ambientes não-formais é pautada na voluntariedade de participação e na inexistência de avaliação de aquisição de conteúdo (OLIVEIRA \& MOURA, 2005). Silva e Carneiro (2006) destacam que a conduta escolarizante manifesta-se de forma crescente em espaços não-formais, com visitas cada vez mais sistematizadas. Nesse sentido, é importante compreender que esses espaços não devem assumir uma função didática como as atividades educacionais que são desenvolvidas pela escola.

Em um espaço não-formal, ao deixar a sala de aula com sua organização típica, o professor se desprende desse papel de detentor do conhecimento, definido pelo modelo tradicional de ensino (CAZELLI et al, 1999; FAHL, 2003) e se sente mais à vontade para estabelecer uma relação horizontal de saber com os alunos. Quando perguntadas sobre sua atuação docente em espaços não-formais as professoras pontuaram que a presença delas deve "[...] agucar a curiosidade de seus alunos." (P1), "Como a de alguém que também aprende com as observações feitas pelos alunos." (P7) além de "[...] instigar e orientar a observação." (P6). A interação, a troca de conhecimentos e experiências, o desejo dos alunos e professores de aprenderem juntos sobre temas específicos podem ser o catalisador para o sucesso de ações em espaços não-formais pois, ao se envolver com o objeto de estudo, o aluno torna-se coadjuvante na aquisição de conhecimento (OLIVEIRA \& MOURA, 2005).

As visitas a espaços não-formais, entendidas pelas professoras como locais fora da escola, ocorrem em média de uma a duas vezes ao ano, principalmente a locais onde elas já conhecem as atividades que são oferecidas. Para uma das professoras "[...] é muito complicado tirar o aluno da escola para você chegar ao local e não saber o que vai encontrar." (P3). Se o professor tem em mente que a visita ao Museu deve estar inserida no conteúdo programático, levando ao aprendizado de determinados tópicos, deve procurar preparar cuidadosamente essa visita, assim o sucesso da Educação não-formal também depende de um bom planejamento (VIEIRA et al, 2005). Para isso, o professor deve visitar previamente a exposição e conhecer as atividades ali propostas para incluí-las em sua proposta pedagógica (VIEIRA, 2005). Essa visita prévia deve existir não só para que o professor se familiarize com o acervo e o espaço, mas para saber se a visita é de interesse e necessidades dos alunos (SILVA \& CARNEIRO, 2006)

As professoras mais uma vez afirmaram que esses espaços são ótimos para atrair a atenção dos alunos para aprender Ciências, mas ressaltando esse espaço como um local de prática "[...] o aluno aprende, na prática, aquilo que ele vê sem sala de aula e, consequentemente, irá aplicar este conhecimento no seu dia a dia. Pode-se concluir, então, que a utilização do Museu da DICA para fins didáticos em Ciências é uma ferramenta importante para o enriquecimento do aluno."(P1), "Atividades práticas são sempre bem vindas para ajudar no Ensino de Ciências." (P4), "É um espaço descontraído que poderá sistematizar vários conceitos trabalhados em sala de aula."(P5).

$\mathrm{Na}$ fala da P5 surge a palavra sistematizar que é muito utilizada nos processos de planejamento das atividades educativas nos espaços formais, o que 
reforça que a linha de diferença entre os espaços formais e não-formais de Educação não é bem delimitada pela professora.

\section{Avaliação da atividade de Botânica}

Para essa análise foram consideradas as observações durante a atividade no espaço DICA, as respostas dos Questionários II, além de anotações do diário de campo.

As professoras foram convidadas a participar da atividade "Chá de Sentidos" como avaliadoras do potencial da mesma para abordagem do conteúdo de Botânica (Fig. 2). Mas o comportamento observado foi o de visitantes comuns do museu, com posturas e falas semelhantes àquelas encontradas no público que participou da atividade em outros eventos (FARIA et al, 2008), tais como "[...] desde o início foi um desafio aos meus sentidos, o que me estimulou a participar." (P2). Isso mostra que as professoras se integram a atividade instigadas pela curiosidade e pelo estímulo ao desafio.

Durante a realização da atividade, ao escolherem uma das caixas para sentir o cheiro da erva ali contida, elas logo colocaram suas opiniões, numa certa urgência em relatar que sabiam de qual planta se tratava (Figura 2 A, B e C). A professora P1 suspeitou ser hortelã, mas acabou relatando dúvidas ao ver a folha. A professora P3 rapidamente disse ter certeza da erva que tinha escolhido e inclusive para quê comumente as pessoas costumam se utilizar daquele chá. A necessidade de demonstrarem conhecimento nos revela que a aprendizagem das professoras está ligada a sua experiência e conhecimentos anteriores, como apontado por Gaspar (1993).

As etapas seguintes foram avaliadas pelas professoras como mais complicadas ou difíceis. Quanto à relação da folha encontrada na caixa escolhida com a cor do chá, as professoras revelaram dificuldade fazer tal ligação devido a semelhança na cor das bebidas. Quanto ao paladar, sentiram dificuldades pelo fato de estarem com o nariz tampado e todas concordaram que, utilizando o aroma se sentiram mais à vontade na identificação. Vendar os olhos e tapar o nariz causou uma certa estranheza, provocando risos e, ao tomar o chá, a professora P4 disse que sem o olfato o paladar não funcionaria bem. Todas demonstraram receio para tentar identificar qual era o gosto. A professora P4 relatou "[...] é tudo difícil sem o nariz [...]" enquanto P2 falou "[...] eu consegui diferenciar mais facilmente porque eu acabei sentindo o cheiro.".

No canteiro das ervas aromáticas as professoras logo foram tocando as plantas à procura de qual seria aquela que elas haviam sentido o cheiro (Figura 2 D). A professora P1 reconheceu a sua rapidamente como sendo hortelã e ficou muito animada. No entanto, algumas delas se confundiram ao relacionarem as que escolheram na Atividade do Chá com as ervas do canteiro. A professora P2 que identificou o chá experimentado como de orégano, ao explorar o canteiro se mostrou surpresa ao sentir o odor do poejo e ficou impressionada por não 
conhecer a erva. A professora P3, que identificou o aroma e o chá como se fosse da planta levante, se sentiu surpresa ao descobrir que se tratava de poejo "[...] é poejo e não levante, minha mãe tinha essas ervas no quintal, me confundi com os nomes, mas eu sabia o que era o poejo é o das folhas miudinhas.". A professora P1 relatou que já tinha escutado falar das ervas que compõem o canteiro, mas que algumas “[...] só conhecia das prateleiras do supermercado em saquinhos.”. P5 se mostrou confusa em diferenciar entre a hortelã e a erva cidreira quando observou sem tocá-la, depois acabou chegando a uma conclusão "[...] conhecia só o capim cidreira, a folha de erva cidreira se parece muito com a hortelã, mas se você pega, logo percebe a diferença, além do cheiro." Durante a atividade as professoras perguntaram bastante sobre o nome de cada erva.

Figura 2. (A) Materiais utilizados para a realização da atividade (B) e (C) Professoras participando da atividade "Chá dos sentidos"

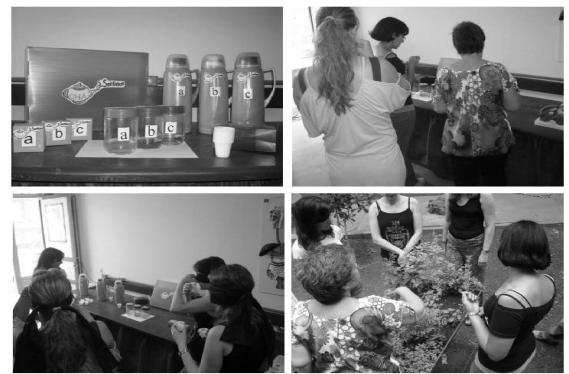

A busca em utilizar o conhecimento prévio sobre as plantas durante as atividades revelou uma preocupação com os nomes das espécies, o que é, geralmente, observada nos professores de Ciências e Biologia que sempre associam a dificuldade de ensinar e aprender Botânica com a grande quantidade de nomes (KINOSHITA et al, 2006). Considerando que historicamente a Botânica foi apresentada a partir de critérios nomenclaturais e descritivos (SILVA, 2008), encontramos dificuldades em abordar os estudos dos vegetais a partir das relações desses seres vivos com o ambiente, por exemplo. Esse comportamento, apresentado pelas professoras, mostra ainda uma preocupação com o conhecimento científico adquirido em sua formação.

A atividade foi considerada simples, mas nem por isso desestimulante. A professora P3 questionou se não deveriam ser utilizadas ervas mais conhecidas, isso porque, provavelmente seus alunos não saberiam reconhecer as apresentadas, já que ela própria apresentou certa dificuldade em fazê-lo. Apesar do foco da atividade estar voltado para o estímulo dos sentidos e para a busca por deflagrar no participante a curiosidade em conhecer os vegetais, as professoras não relacionaram essas intenções às propostas de abordagem do conteúdo. As visitantes buscaram, o tempo todo, combinar os sentidos para se localizarem e 
realizarem a atividade com êxito, considerando que as associações corretas é que devem ser alcançadas, mas se preocuparam mais com os acertos.

Após realizarem a atividade, todas as professoras consideraram ser possível aplicá-la na sala de aula para tratar de assuntos relacionados à Botânica, mas se associando a atividade com pesquisas acerca das plantas a serem realizadas pelos alunos. As respostas do Questionário II não revelaram associações das professoras sobre o conhecimento adquirido em relação ao potencial da atividade com as possíveis formas de abordagem dos conceitos pertinentes ao conteúdo de Botânica.

Entre as sugestões para a atividade, algumas professoras se mostraram preocupadas com o tempo de realização da mesma "[...] deveria reduz̧ir para dois chás." (P5) e com relação à capacidade dos alunos de acertarem o nome da planta "[...] talvez utilizar plantas mais comuns, como o capim-cidreira. Porque é dificil o menino que conhece e toma chá." (P3). Ao se preocuparem com o tipo de erva a ser utilizado ou mesmo o número dessas na atividade, o professor se mostra preso à formalidade imposta pelos planejamentos curriculares e de seu papel facilitador do aprendizado e se afasta da simplicidade da atividade para aguçar os sentidos, gerar prazer ou desconforto e, concomitantemente, despertar interesse pelas plantas ao brincar com seus sentidos. Percebe-se a preocupação com o tempo além do receio da professora em colocar seus alunos em situações conflituosas. As professoras, presas às questões da necessidade de um conhecimento prévio sobre plantas, refletem seu comportamento revelado na atividade e se fixam à preocupação dos acertos dos alunos como uma forma de mantê-los empolgados pela atividade e não percebem que a proposta é de que o participante se deixe envolver e a conhecer os vegetais pelos sentidos. Considerando que depois de associarem aromas e cores aos vegetais os alunos terão acesso a um canteiro onde entrarão em contato com as ervas, não há problema se eles conheciam ou não a planta antes da atividade. Muitas professoras passaram por essa situação e se mostraram muito interessadas na busca de informações sobre as plantas que não conheciam.

Oferecer oportunidades para que os alunos se sintam estimulados possibilita o desenvolvimento de um ensino onde esses são os próprios protagonistas de seu aprendizado. Faria et alli (2008), ao apresentar a atividade "Chá dos Sentidos" como introdução para a abordagem do conteúdo de Ciências para alunos do sétimo ano (sexta série) do Ensino Fundamental, mostrou que o interesse pela observação e o estímulo ao uso dos sentidos foi muito elevado e duradouro em aulas seguintes em que os alunos se sentiam seguros e motivados a interagirem com as amostras de plantas utilizadas nas aulas.

A oportunidade de ver as plantas in natura se apresentou como um fator de atração para as professoras e consideraram que o mesmo aconteceria com os alunos “[...] porque eles teriam oportunidade de "ver" as plantas no canteiro." (P3). O que se percebe nas escolas é uma dificuldade em proporcionar o contato dos alunos com o ambiente natural e, assim, o estudo das plantas passou a ser tão 
teórico e complexo que acabou por desestimular o estudo do tema (SILVA \& CAVASSAN, 2008). Klein e et alli (2006) revelaram que os alunos têm pouco contato com plantas e o conhecimento que alguns possuem foram repassados pelos familiares, principalmente pelos seus avós e tios. No entanto, esses conhecimentos, muitas vezes relacionados ao uso e cultivo de plantas medicinais, estão cada vez mais raros visto que o uso destas é raro em detrimento aos medicamentos sintéticos (ARNOUS et al, 2005) e também devido à falta de diálogo entre as gerações pode estar prejudicando a transmissão do conhecimento de plantas medicinais aos mais jovens (AMARAL et al. 2006).

A utilização de canteiros atenderia à necessidade apontada pelas professoras de oportunizar o "ver" pelos alunos. Além disso, ajudaria a romper com a ideia de que só percebemos através dos olhos, como se os outros sentidos estivessem adormecidos (BAPTISTA et al, 2005). Silveira et alli (2006) mostraram que, quando estimuladas a observar e relacionar as plantas com o ambiente, as crianças conseguem perceber melhor as plantas do entorno onde vivem.

Nesse sentido, Wykrota e Nascimento (1994) afirmam ser essencial que o aluno primeiro interaja com a planta como um todo, inserida no seu meio, para facilitar a valorização da vegetação natural e a compreensão do seu papel na manutenção da qualidade do ambiente.

Considerando o espaço DICA verificamos as dificuldades demonstradas pelas professoras ao pensar na atividade em relação ao espaço de Educação não-formal, mas acreditamos que esse seja um ponto importante no que diz respeito à forma de como os museus podem se relacionar com esse público. Ao se mostrar interessado nesse diálogo com os professores, os Museus podem aparecer como importantes locais para formação inicial e continuada.

As professoras reconhecem que aquele espaço não tem objetivo curricular, mas a atividade é associada com o que o aluno deve aprender. A intenção é que a atividade desperte a atenção para outras formas de aprendizagem ao lidar com as plantas, como percebido por P2 "[...] eu traria a atividade para sala de aula em forma de discussão e como exemplo para explicar a diversidade de plantas e suas características (forma da folha, cheiro, cor, gosto, etc).”.

Outro aspecto interessante ressaltado por uma das professoras " [...] ao término da mesma, cheguei à conclusão da importância da interação dos cinco sentidos e que, apesar da possibilidade de agirmos na ausência de alguns deles, a interação ainda ocorre. Devese ressaltar, também, que na "ausência" de um ou mais sentidos, aqueles que "permanecem" tendem a ser mais desenvolvidos." (P1), nos levou a considerar que a atividade despertou a percepção da necessidade de estarmos atentos às diferenças apresentadas pelas pessoas, o que é de fundamental importância para que se estabeleça o processo de ensino aprendizagem. 


\section{CONSIDERAÇÕES FINAIS}

A pesquisa proporcionou uma amostra das concepções que as professoras da cidade de Uberlândia (MG) possuem sobre espaços de Educação formal e não-formal. Isso se torna importante a partir do momento em que a cidade conta com a presença desses espaços de Educação não-formal, como o Museu de Biodiversidade do Cerrado, o Museu de Rochas e Minerais e o Museu Diversão com Ciência e Arte, que tem como público principal os escolares.

Ao detectar o que as professoras esperam desses espaços, suas equipes podem, de alguma forma, promover ações para que as professoras compreendam as propostas desses locais e apontá-los como mais um local propício ao Ensino, porém com suas peculiaridades. Essa troca pode permitir que espaços não-formais como os Museus de Ciências sejam melhor aproveitados.

A dificuldade em conceituar e distinguir o espaço formal do não-formal pode ser gerada em função da pauta de discussão estar centrada na roda da pesquisa em Educação, sem que esses questionamentos sejam amplamente divulgados entre os professores do Ensino Básico. Dessa forma, os professores acabam por adotar um conceito baseado mais no senso comum ligado ao formalismo e à própria organização do espaço físico que deve ser adotado na sala de aula.

A atividade de Botânica dentro de um espaço não-formal foi avaliada positivamente pelas professoras. No entanto, existe uma dificuldade em considerar a atividade como uma proposta para se estimular os sentidos e assim obter um processo de aprendizado mais envolvente e interativo. As professoras, mesmo que em um ambiente distinto da escola, preservam a responsabilidade com o aprendizado do seu aluno baseado no que está posto pelo currículo e, assim, acabam buscando na atividade uma forma de trabalhar o conteúdo e não de simplesmente deflagrar o interesse pelos vegetais e ampliar as possibilidades de aprendizado de seus alunos relacionando as experiências vivenciadas fora da escola com as em sala de aula.

Contudo, acreditamos que, de alguma forma, após passarem por essa atividade, essas professoras, mesmo que não imediatamente, tenham se sensibilizado para outras formas de tornar o Ensino de Botânica mais prazeroso. 


\section{NOTA}

1 Utilizaremos nesse texto a definição de concepções adotada por CUNHA (2001), que engloba como as professoras compreendem e utilizam de ideias conceituais.

\section{REFERÊNCIAS BIBLIOGRÁFICAS}

ALMEIDA, A. M. Desafios da relação museu-escola. Comunicação e escola, v. 10, p. 50-57, 1997. AMARALIn: 57 CONGRESSO NACIONAL DE BOTÂNICA, 2006, Gramado-RS. Resumos... Gramado: FAURGS, 2006. 1 CD-ROM

ARNOUS, A. H.; SANTOS, A.S.; BEINNER, R. P. C. Plantas medicinais de uso caseiro -conhecimento popular e interesse por cultivo comunitário. Revista Espaço para Saúde, v. 6, n. 2, p. 1-6, 2005.

BAPTISTA, A. S.; FRANÇÃO, P.; MARCHESE, D. M. A. Jardim Sensorial. In:CONGRESSO INTERNACIONAL DE MEDICINA E REABILITAÇÃO DA AACD. CONGRESSO DE REABILITAÇÃO DA ORITEL, 3 e 5. , 2005, São Paulo. Resumos... São Paulo: AACD, 2005.

BRASIL. Secretaria de Educação Média e Tecnológica. Parâmetros Curriculares Nacionais - PCN's, Brasília: MEC, 1997.

CAZELLI, S., et al.Tendências pedagógicas das exposições de um Museu de Ciências. In: SEMINÁRIO INTERNACIONAL DE IMPLANTAÇÃO DE CENTROS E MUSEUS DE CIÊNCIAS, 1999. Rio de Janeiro. Implantação de Centros e Museus de Ciências.Rio de Janeiro:UFRJ, 1999.

CUNHA, A. M. O. A mudança epistemológica de professores num contexto de Educação Continuada. Ciência e Educaşão, v. 7, n. 2, p. 235-248, 2001.

FAHL, D. D. Marcas do Ensino escolar de Ciências presentes em Museus e Centros de Ciências: um estudo da Estação Ciência - São Paulo e do Museu Dinâmico de Ciências de Campinas (MDCC). 2003. Dissertação (Mestrado) - Faculdade de Educação, Universidade Estadual de Campinas, Campinas, 2003

FARIA, R. L., et al. Aprendendo botânica através dos cinco sentidos. In: CONGRESSO NACIONAL DE BOTÂNICA, 59, 2008 . Natal-RN. Resumos... Rio Natal: SBB, 2008. 1CD ROOM.

FERNANDES, R. S.; GARCIA, V. A. Educação não formal campo de em formação. Revista Profissãa Docente (online), v. 6, n. 13, 2006.

GASPAR, A. Museus e Centros de Ciências: conceituação e proposta de um referencial teórico. 1993. Tese (Doutorado em Didática) - Faculdade de Educação, Universidade de São Paulo, São Paulo, 1993. GOHN, M. G. Educação não-formal, participação da sociedade civil e estruturas colegiadas nas escolas. Ensaio: Avaliação e Politicas Públicas em Educação, v. 14, n. 50, p. 27-38, 2006.

GOUVÊA, G., et al. Redes cotidianas de conhecimentos e os Museus de Ciências. Parcerias Estratégicas, n. 11, p. 169-174, 2001.

GRUZMAN, C.; SIQUEIRA, V. H. F. O papel educacional do Museu de Ciências:desafios e transformações conceituais. Revista Electrónica de Enseñanza de las Ciências, v. 6, n. 2, p. 402-423, 2007.

GUIMARÃES, M.; VASCONCELLOS, M. M. N. Relações entre Educação Ambiental e Educação em Ciências na complementaridade dos espaços formais e não formais de Educação. Educar, n. 27, p. 147-162, 2006.

JACOBUCCI, D. F. C. Contribuições dos espaços não-formais de Educação para formação da cultura científica. Em Extensão, v. 7, p. 55-66, 2008.

KINOSHITA, L. S., et al. A Botânica no Ensino Básico: relatos de uma experiência transformadora. São Paulo: Rima, 2006.

KLEIN, E. S., et al.Descobrindo as plantas medicinais, aromáticas e ornamentais. In: KINOSHITA, L.S., et al. A Botânica no Ensino Básico: relatos de uma experiência transformadora. São Carlos: RiMa, 2006.

KRASILCHIK, M. Prática de ensino de Biologia. 4 ed.. São Paulo: Editora USP, 2004.

LAVILLE, C.; DIONNE, J. A construção do saber. Belo Horizonte: UFMG, 1999. 
LÜDKE, M.; ANDRÉ, M.E.D.A. Pesquisa em Educação: abordagens qualitativas. São Paulo: Editora Pedagógica e Universitária, 1986.

MARANDINO, M. Biologia nos Museus de Ciências: a questão dos textos em bioexposições. Ciência e Educação, v. 8, n. 2, p. 187-202, 2002.

Enfoques de Educação e comunicação nas bioexposições de Museus de Ciências.

Revista Brasileira de Pesquisa Em Educação Em Ciências, v. 3, n. 1, p. 103-109, 2003.

MINAYO, M. C. S.; DESLANDES, S. F.; GOMES, R. Pesquisa Social: Teoria, método e criatividade. 26 ed. Petrópolis: Editora Vozes, 2007.

OLIVEIRA, C. L.; MOURA, D. G. Projeto Trilhos Marinhos: uma abordagem de ambientes nãoformais de aprendizagem através da Metodologia de Projetos. Educação \& Tecnologia, v. 10, n. 2, p. 46-51, 2005.

QUEIROZ, G., GOUVÊA, G., FRANCO, C. Formação de professores e Museus de Ciências. In: Educação e Museu: a construção social do caráter educativo dos Museus de Ciências. Rio de Janeiro: Editora Acess, 2003.

SILVA, M. R.; CARNEIRO, M. H. S. Popularização da Ciência: Análise de uma situação não-formal de Ensino. In: ASSOCIAÇÃO NACIONAL DE PÓS-GRADUAÇÃO E PESQUISA EM EDUCAÇÃO (ANPED), 29., 2006, Caxambu. Anais da 29 Reunião anual da Anped.Caxambu, ANPED, 2006.

SILVA, P. G. P. O Ensino da Botânica no nivel fundamental: um enfoque nos procedimentos metodológicos. 2008. 146 f. Tese (Doutorado) - Faculdade de Ciências, Universidade Estadual Paulista, Bauru, 2008.

SILVEIRA, V. C., et al. Currículo em (Re)construção. In: KINOSHITA, L. S., et al. A Botânica no Ensino Básico: relatos de uma experiência transformadora. São Carlos: RiMa, 2006.

VIEIRA, V. S. Análise de espaços não-formais e sua contribuição para o ensino de Ciências. 2005. Tese (Doutorado em Ciências) - Área de Concentração em Educação, Gestão e Difusão em Biociências. Instituto de Bioquímica Médica - Universidade Federal do Rio de Janeiro, UFRJ, Rio de Janeiro, 2005.

VIEIRA, V.; BIANCONI, M.; DIAS, M. Espaços não-formais de Ensino e o currículo de Ciências. Ciência e Cultura, v. 57, n. 4, p. 21-23, 2005.

WANDERSEE, J. H; SCHUSSLER, E. E. Towards a theory of plant blindness. Plant Science Bulletin, v. 47, n. 1, p. 2-9. 2001.

SILVA, P. G. P. O ensino da botânica no Nivel Fundamental: um enfoque nos procedimentos metodológicos. 2008. Tese (Doutorado em Educação para a Ciência). Universidade Estadual Paulista Júlio de Mesquita Filho, UNESP, 2008.

WYKROTA, J. L. M.; NASCIMENTO, S. S. Conhecendo uma árvore. Presença Pedagógica, ano 1, n. 1, p. 45-55, 1995. 
